\title{
Reduction of winding AC losses by accurate conductor placement in High frequency Electrical Machines
}

\author{
Anuvav Bardalai ${ }^{1,2}$, David Gerada ${ }^{1}$, Dmitry Golovanov ${ }^{1}$, Zeyuan $\mathrm{Xu}^{1}$, Xiaochen Zhang ${ }^{1}$, \\ Jing Li $^{2}$, He Zhang ${ }^{2}$, Chris Gerada ${ }^{1}$ \\ Department of Electrical and Electronic Engineering, The University of Nottingham, UK ${ }^{1}$ \\ Faculty of Science and Engineering, The University of Nottingham Ningbo, China ${ }^{2}$
}

\begin{abstract}
In the design of electrical machines, the increase of power density has become one of the main research themes. With most of the power loss in high power density electrical machines often being generated in the stator winding assembly, it is necessary to reduce these losses. The effects of strands and bundle positions in the slot on the AC losses in the winding are often overlooked. Taking as a case-study an existing high frequency machine, this paper analyzes and provides an in-depth insight into such effects. Exploiting the rapid advancements in precision 3D printing, it is found and experimentally verified that by controlling the position of the conductors within the top of the slot the AC losses can be markedly reduced.
\end{abstract}

Index Terms-- AC copper loss, circulating currents, conductors, eddy current, high power density, optimization, permanent magnet machines, proximity effect, transportation, windings.

\section{INTRODUCTION}

Increasing demands and widespread adoption of electrical drives in aircraft, automobiles and machine tools have intensified efforts in the design and development of high performance electrical machines that combine high power density $(\mathrm{kW} / \mathrm{kg}$ or $\mathrm{kW} / \mathrm{L})$, light-weighting and high efficiency [1]. With the majority of the power loss within high power density electrical machines often being generated in the stator winding [2], it is necessary to reduce the copper losses and improve the heat transfer mechanisms for such losses. One general way of reducing the copper losses is by maximizing the slot filling and achieving better thermal conductivity within the slot [3]. Using rectangular conductors, with higher cross - sectional areas and evenly laying them around segmented stator teeth in the form of preformed coils, coupled with the use of higher thermal conductivity materials can result in achieving the best slot fill and a good thermal performance [4]. Traditionally, the increase of apparent resistance of windings in $\mathrm{AC}$ machines has been neglected or given secondary concern for smaller machines, especially those with a low fundamental frequency. However, for high frequency machines, the apparent AC resistance can become significant and, in many instances, cannot be neglected. The temperature variation because of these added AC affects should also be carefully considered as high concentrations of loss will be accompanied by higher localized temperature variations
[5] - [7] and earlier insulation failures.

The increased AC losses are due to induced currents in the strands resulting from varying linked flux and can be segregated based on the source of the flux. Skin - effect loss in a strand is caused by the AC current flowing in that strand, while when loss in a strand is due to an external imposed field on that strand, they are typically referred to as proximity losses. For machines with regular solid copper strands, the proximity - effect induced losses can be further distinguished into: armature field induced losses and excitation field induced losses.

One of the countermeasures that exist to mitigate these aforesaid AC losses is by using several thinner strands in parallel with the strand diameter chosen to be of a value less than the skin penetration-depth at the operational frequency. However, even with thin wire to eliminate the skin effect, proximity effects can still exist, since parallel paths for coil turns located in the slot top and slot bottom have different flux linkages between them due to higher leakage flux at the slot top. In light of this, another measure is to keep the area very close to the slot opening, where high leakage flux exists, un-wound [8] - [11]. Unfortunately, all the mentioned countermeasures result in reduced slot-filling factor and potentially also increase the production cost. AC losses can be further reduced by using transposed conductors, such as Litz Wire, however the cost of such wire, being approximately ten times that of conventional magnet wire, precludes its use altogether in many cost-sensitive applications, such as those in automotive.

Proximity losses in high speed electrical machines is a well-studied researched area [10], [12] - [19]. While in [10], the influence of conductor shape on the proximity losses is investigated, vanDerGeest in [12], analysed the effect of varied number of parallel strands, partially filled slots, strand shape, fill factor and slot size on proximity loss and inferred that the AC losses in strands of different shapes (circular, hexagonal, square) but with same area are virtually identical. In [14], the authors investigated a variety of winding connections at different speeds and studied the proximity losses with circulating currents and strands in hand for rectangular conductors.

Proximity losses caused by the excitation field primarily effects machines with windings in direct exposure to the field flux, such as slotless machines and 
these losses also need to be considered in machines without tooth tips [20]. The AC losses caused by the excitation field greatly diminish in the presence of the tooth tip and in such instances the modelling and experimental verification can be simplified.

For low-voltage machines with random windings the proximity losses caused by the flux leakage are sensitive to the positions of strands. However, the effects due to varied positions of these strands-in-hand for random windings have not been widely looked into, as these have been traditionally regarded as too laborious or even impossible to control in practice. In this work, the influence of such magnet wire arrangements both at the strand and bundle levels on the AC losses in the winding of the machine are investigated with the aim of achieving an improved layout of conductors with reduced losses.

This paper is organized as follows: Section II introduces the high-speed machine under investigation and its numerical modeling for AC loss calculation. Section III presents the analysis results. Experimental validation of the improved layout is presented in Section IV, and conclusions of this research are finally summarized in Section V.

\section{MACHINE SPECIFICATION AND ITS MODELLING}

An existing high-speed traction machine, the details of which are listed in Table I, is used for the analysis in this paper. The machine has 12 slots and 8 poles with a corresponding maximum fundamental frequency of 1.5 $\mathrm{kHz}$.

TABLE I

MACHINE PARAMETERS

\begin{tabular}{cc}
\hline \hline Parameter & Specification \\
\hline \hline Machine Type & Three - phase PMSM \\
Rotor type & Interior Flat \\
Magnet Material & N38EH \\
Peak power & $74 \mathrm{~kW}$ \\
Rated torque & $126 \mathrm{Nm}$ \\
Rated / maximum speed & $2800 / 23000 \mathrm{rpm}$ \\
No. of Slots & 12 \\
No. of Poles & 8 \\
Stack length & $140 \mathrm{~mm}$ \\
Winding Type & Concentrated \\
Parallel path & 1 \\
Layers & 2 \\
No. of turns/slot & 20 \\
Strands - in - hand & 33 \\
Strand Type & Round Magnet Wire \\
Strand Diameter & $0.704 \mathrm{~mm}$ \\
Strand Nominal diameter & $0.63 \mathrm{~mm}$ \\
Slot Filling Factor & $44.5 \%$ \\
Efficiency & $\geq 95 \%$ \\
Cooling Type & Water Jacket Cooling \\
Working Temperature & $-40 \sim 105^{\circ} \mathrm{C}$ \\
\hline \hline
\end{tabular}

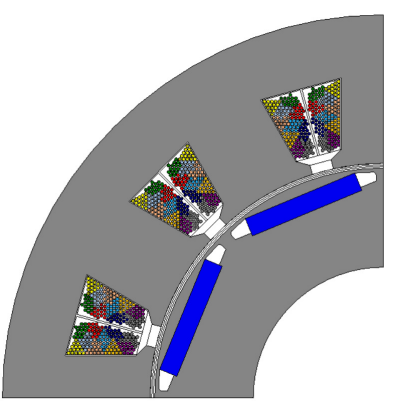

(a) 3 slots 3 phases

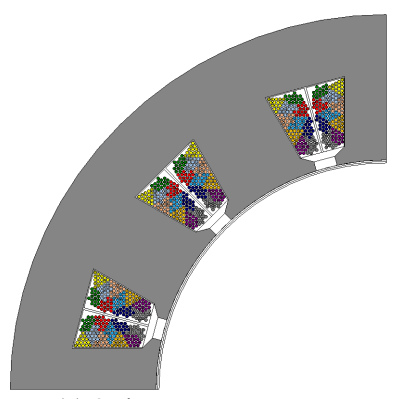

(c) 3 slots no rotor

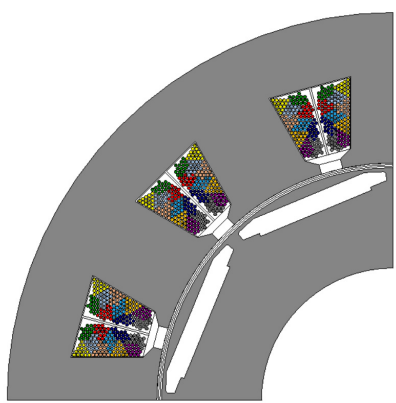

(b) 3 slots no magnet

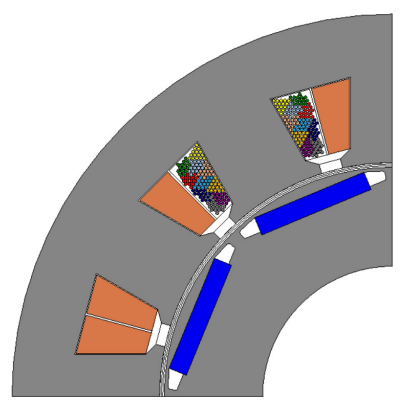

(d) 3 slots 1 phase stranded

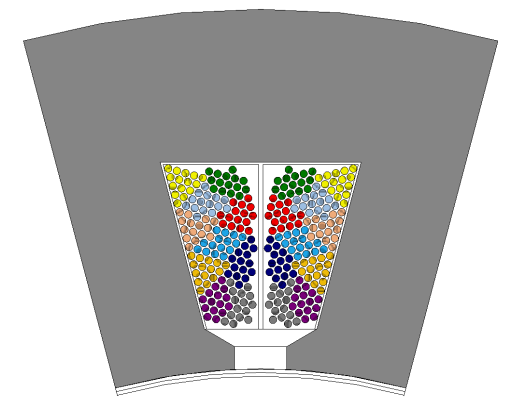

(e) 1 slot stranded

Fig. 1. Comparison of models for simplification

\section{A. Simplification of Modelling}

Modelling and solving machine finite element analysis (FEA) models at the strand-level is computationally highly expensive and at times not possible. Therefore, simplification of models is desired. The first level of simplification involves modelling all the strands within the slots while exploiting periodic symmetry as common with the FEA analysis of all electrical machines, as shown in Fig. 1a, where a quarter of the machine is modelled.

TABLE II

MODELS LOSS COMPARISON

\begin{tabular}{ccc}
\hline \hline Models & $\begin{array}{c}\text { Total losses in active } \\
\text { length of machine (W) }\end{array}$ & $\begin{array}{c}\text { \% difference from } \\
\text { Base model }\end{array}$ \\
\hline \hline 3 slots 3 phases & 623.12 & 0 \\
3 slots no magnet & 612.15 & -1.76 \\
3 slots no rotor & 615.03 & -1.30 \\
3 slots 1 phase stranded & 445.16 & -28.56 \\
1 slot stranded & 652.38 & 4.70 \\
\hline \hline
\end{tabular}


This is used as a baseline for evaluating the loss of accuracy with further simplification levels, as shown in Fig. $1 \mathrm{~b}$ to Fig. 1e, and subsequently quantified in TABLE II.

In Fig. 1b, the magnets (source of excitation flux) are removed in comparison to the baseline model, while in Fig. 1c the rotor is removed altogether, with marginal reduction in $\mathrm{AC}$ loss prediction accuracy, confirming that the effect of the excitation field is insignificant in machines with tooth tips and smaller slot opening as it only reduces the losses by $1.3 \%$ in comparison to the baseline model. For Fig. 1d, only one phase is modelled at the strand-level and the currents in the two other phases are adjusted to maintain the same ampere-turns as in the

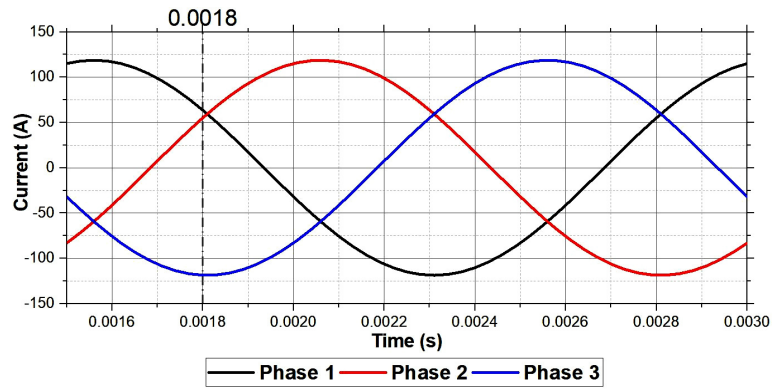

(a)

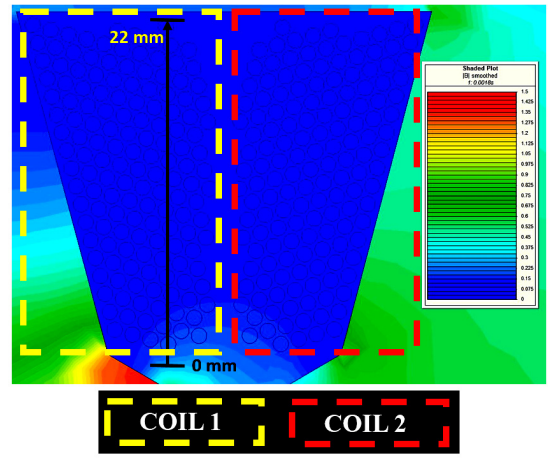

(b)

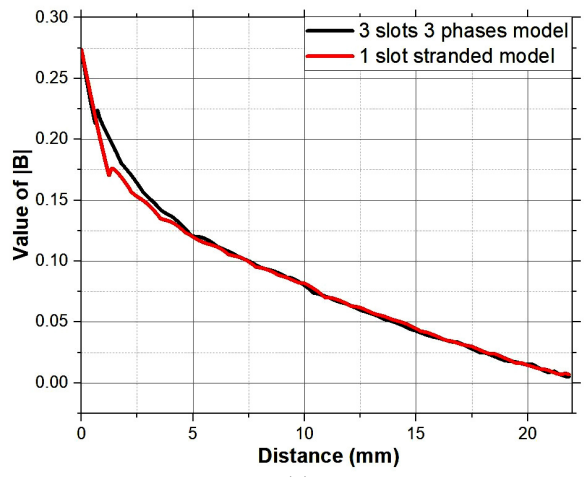

(c)

Fig. 2. (a) Waveform of 3 phase source current with timeline marked at $0.0018 \mathrm{~s}$, (b) Flux density $|\mathrm{B}|$ measurement inside the slot of the models, (c) Comparison of Flux density $|\mathrm{B}|$ inside the slot of 1 slot stranded model with the baseline model at time instant $0.0018 \mathrm{~s}$ baseline model, however this results in a significant drop in accuracy due to the effect of flux distribution in the slot associated with modelling solid lumped conductors. In Fig. 1e, only a single slot with half coil sides of either phase is modelled, resulting in a marked reduction in simulation time and less than $5 \%$ difference in loss prediction with respect to the baseline model.

Fig. 2 provides further detailed insight into this simplification, showing similar flux densities at different regions of the slot for both the baseline model and the single slot model, hence the single slot model is used for further analysis and strand position optimization within this paper.

\section{B. Conductor placement}

In this work an algorithm is developed for automatic conductor placement within the slot, as described below:

- The given slot geometry is filled with discs to imitate magnet wires and the position of each disc is fixed and stored. The distance between any two adjacent discs accounts for the magnet wire's enamel insulation thickness and a minimum separation corresponding to a realistic copper filling factor.

- The discs are then clustered to form bundles which occupy different positions within the slot geometry.

- The bundles are connected in series to form turns and the strands within a bundle form the parallel paths/ strands-in-hand.

- The clustering of the discs is varied as such that the bundles form different shapes and take varied

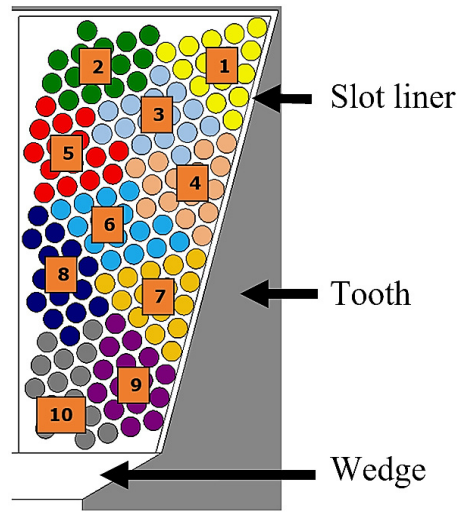

Fig. 3. Half side of the slot showing section of teeth, wedge, slot liner, strands and bundles

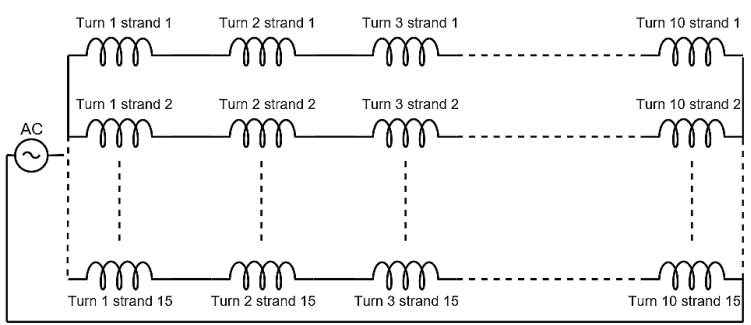

Fig. 4. Circuital representation of the strands and bundle connection 
positions in the slot, resulting in numerous plausible bundle positions.

- The shapes of the bundles are not constrained in an effort to achieve a good resemblance to a random hand-wound winding.

Fig. 3 shows half side of a slot. Here, each colored disc represents a strand. A cluster of discs of the same color represents half side of a turn, with the identically colored discs representing parallel strands within a bundle. The number designated to each bundle signifies the turn number and its position within the slot. A circuital representation of the strands and bundle connection is shown in Fig. 4.

\section{SimULATION RESULTS}

The analysis in this section is carried out using a model consisting of 10 turns per coil, with each bundle made up of 15 strands-in-hand, resulting in 150 strands per half slot. Magnet wires with a nominal strand diameter of 1 $\mathrm{mm}$ are chosen to give a slot filling factor of $55 \%$ and an rms current of $84 \mathrm{~A}$ with a frequency of $1500 \mathrm{~Hz}$ is applied.

Four versions of plausible bundle positions are considered for the analysis as shown in Fig. 5. TABLE III shows the total losses in the active length of the winding

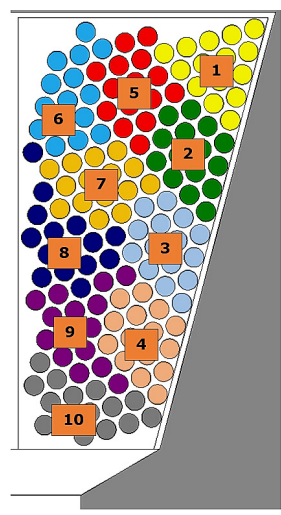

(a) Version\#1

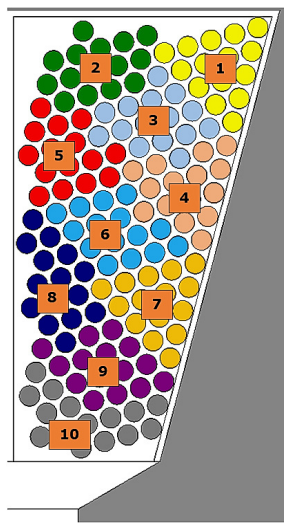

(c) Version\#3 (b) Version\#2

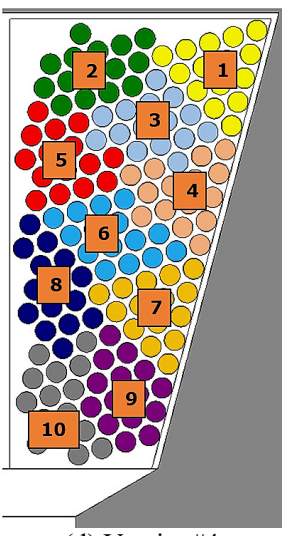

(d) Version\#4

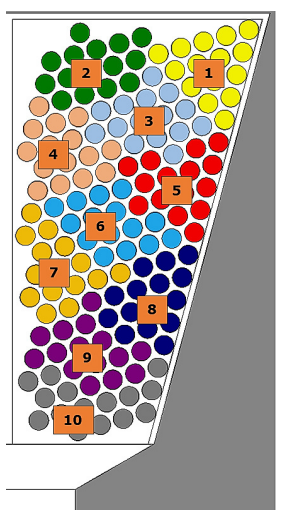

Fig. 5. Half side of a slot showing four plausible versions of bundle positions
TABLE III

COMPARISON OF TOTAL LOSS TO DC LOSS

\begin{tabular}{ccc}
\hline \hline Versions & Total Loss $(\mathrm{W})$ & Total / DC Loss \\
\hline \hline Version\#1 & 1238.62 & 3.49 \\
Version\#2 & 1289.48 & 3.63 \\
Version\#3 & 1121.42 & 3.16 \\
Version\#4 & 652.38 & 1.84 \\
\hline \hline
\end{tabular}

and total loss to DC loss ratio, with the DC loss in the active length of the winding being $354 \mathrm{~W}$. For versions $\# 1, \# 2$ and \#3 the total loss to DC loss ratio is above 3 times. However, for the case of version \#4 the loss ratio is 1.84 .

Fig. 6a shows the comparison of losses in the conductors for the four versions and Fig. $6 \mathrm{~b}$ shows the averaged out losses in the conductors for each version. The average reduction of losses in the conductors from the worst case (version \#2) to best case (version \#4) is approximately $50 \%$. Also, as evident upon inspection of Fig.5, comparing version \#3 and \#4, only the position of bundles 9 and 10 are changed. However, by doing so the total losses in the winding reduce by approximately $41 \%$. Fig. 7a shows the supply current to one of the phases while Fig. $7 \mathrm{~b}$ and Fig. $7 \mathrm{c}$ show the currents as shared by the strands for version \#3 and \#4 respectively. As can be observed from these figures, the currents in the strands are unevenly distributed and are displaced in time. TABLE IV further details quantitatively the comparison of currents as shared by the strands for version \#3 and version \#4.

Indeed, from Table IV, if in an ideal scenario the

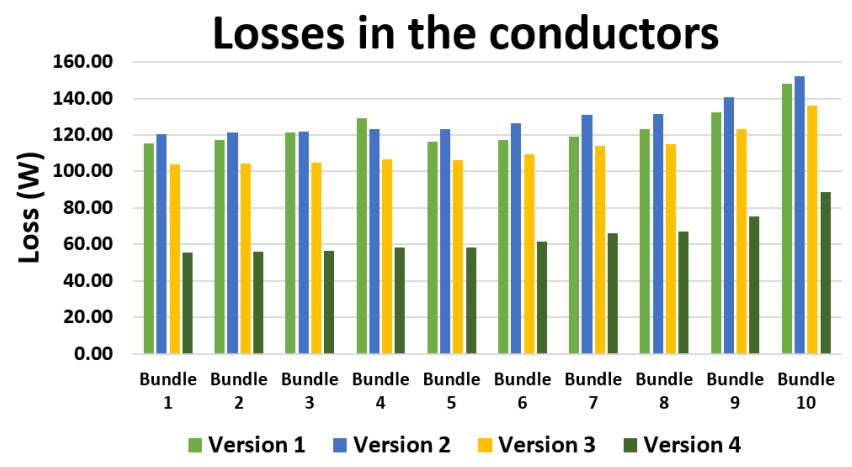

(a)

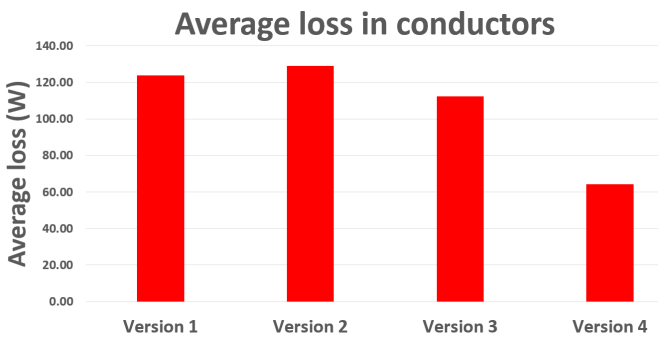

(b)

Fig. 6. (a) Losses in the conductors, (b) Average loss in the conductors for the considered bundle arrangements 
TABLE IV

COMPARISON OF STRAND CURRENTS

\begin{tabular}{ccc}
\hline \hline & Version \#3 & Version \#4 \\
\hline \hline Strand carrying max. current & Strand 13 & Strand 12 \\
Ideal current per strand & \multicolumn{2}{c}{$7.92 \mathrm{~A}$} \\
(A peak) & \multicolumn{2}{c}{} \\
Simulated Current (A peak) & $22.97 \mathrm{~A}$ & $15.73 \mathrm{~A}$ \\
Simulated/ideal ratio & 2.9 & 1.86 \\
Strand carrying min. current & Strand 5 & Strand 2 \\
Simulated amplitude (A peak) & $6.96 \mathrm{~A}$ & $6.41 \mathrm{~A}$ \\
\% difference between max. and min. & $230 \%$ & $145.4 \%$ \\
\hline \hline
\end{tabular}

supply current were to be evenly shared by the strands, then each strand should carry current with a peak amplitude of 7.92A (peak supply current divided by the number of parallel strands). However, due to uneven current sharing, some strands carry more current compared to others. In case of version \#3, the maximum peak current is carried by strand 13 with an amplitude of 22.97A which is 2.9 times the ideal current the strand should be carrying. Strand 5 carries the minimum current,

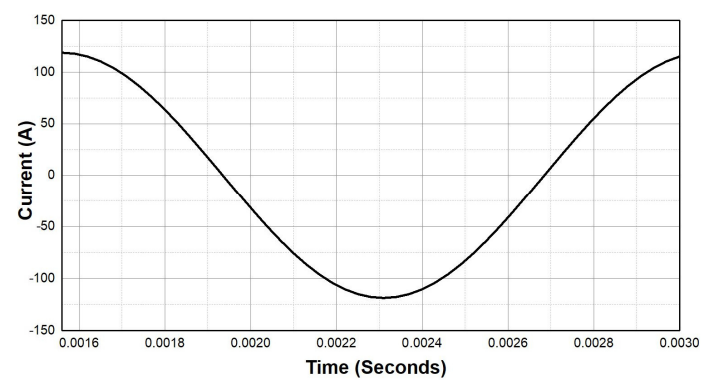

(a) Supply Current

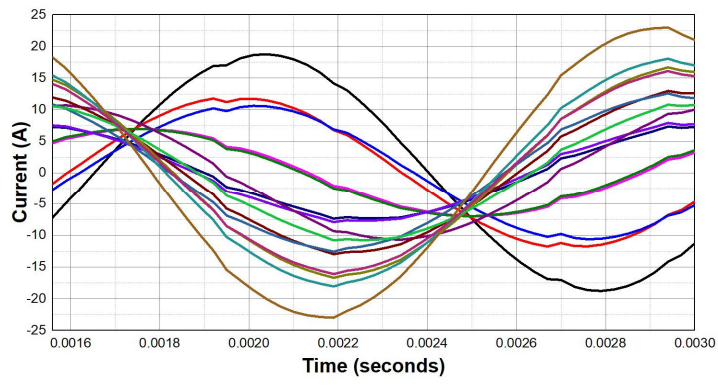

(b) Currents in strands of Version\#3

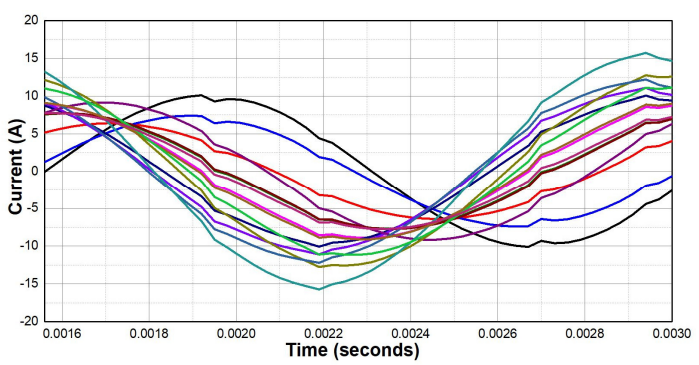

(c) Currents in strands of Version\#4

Fig. 7. Comparison of strand currents in Version \#3 and \#4 along with supply current

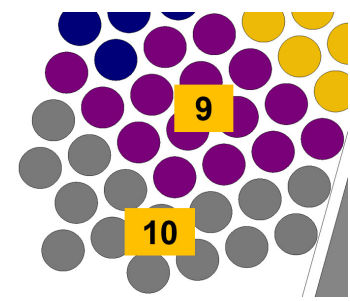

(a)

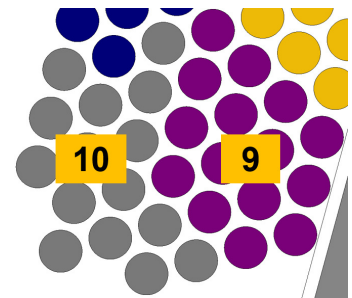

(b)

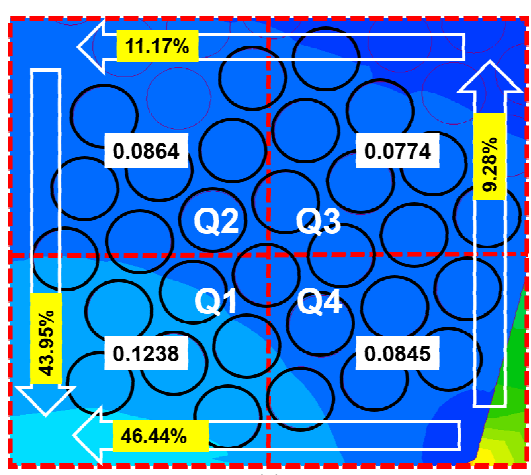

(c)

Fig. 8: (a) Bundles 9 and 10 in Version \#3, (b) Bundles 9 and 10 in Version $\# 4$, and (c) Average value of flux density $|\mathrm{B}|$ in the quadrants

with an amplitude of $6.96 \mathrm{~A}$ and the percentage difference in the current through strand 13 and strand 5 is $230 \%$. In case of version \#4, the maximum current of $15.73 \mathrm{~A}$ and is carried by strand 12 , which is 1.86 times the ideal current, while strand 2 carries the least current with a value of $6.41 \mathrm{~A}$, which is $145.4 \%$ less with respect to the current in strand 12.

An explanation is sought as to why there is this notable difference between the two versions (\#3 and \#4). A preliminary explanation was presented in [21]. In this paper, a more detailed insight into it is presented. Fig. 8a and Fig. 8b show the bundle 9 and 10 positions for version \#3 and \#4 respectively. Considering this region of the slot, in Fig. 8c, the flux density in the region of interest within the slot is plotted with the black bordered circles representing the strands that form bundles 9 and 10 . The region of the slot occupied by these strands is divided into four quadrants, namely, Q1 to Q4. For each quadrant, the average flux density $|\mathrm{B}|$ is calculated over one electrical cycle, with the value of $|\mathrm{B}|$ for each quadrant highlighted in white in Fig. 8c. The percentage change in $|\mathrm{B}|$ from one quadrant to another is highlighted in yellow and enclosed within the white arrows. This change is quite noticeable from Q4 to Q1 at $46.44 \%$ and from Q2 to Q1 at $43.95 \%$, when compared to Q3 to Q2 at $11.17 \%$ and Q4 to Q3 at $9.28 \%$. In version \#3, since the parallel strands of the bundles are placed across Q3 to Q2 and Q4 to Q1, they are subjected to an overall greater variation of flux density among them $(11.17 \%$ for bundle 9 and $46.44 \%$ for bundle $10)$. This greater variation in flux linkage in parallel strands of a bundle results in the impedance of each parallel strand to vary significantly. This in turn leads to circulating currents in the strands causing the problem of 


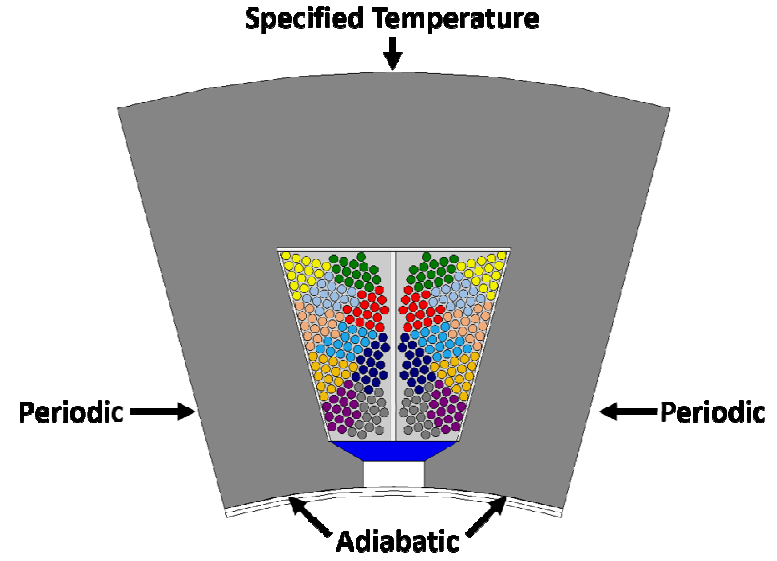

Fig. 9. Boundary conditions applied to the single slot model for thermal FEA

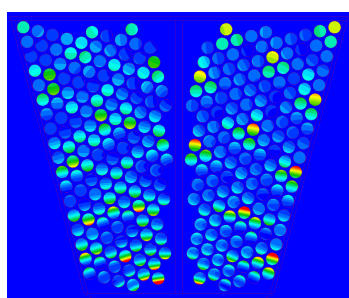

(a)

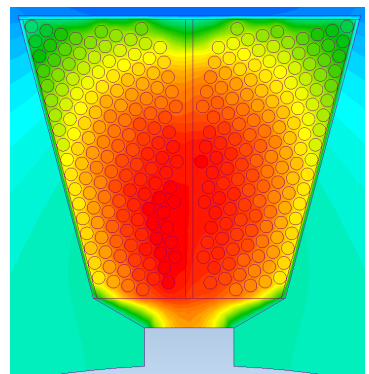

(c)

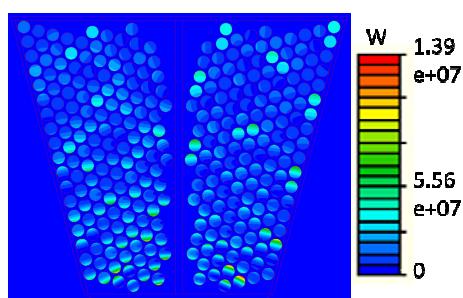

(b)

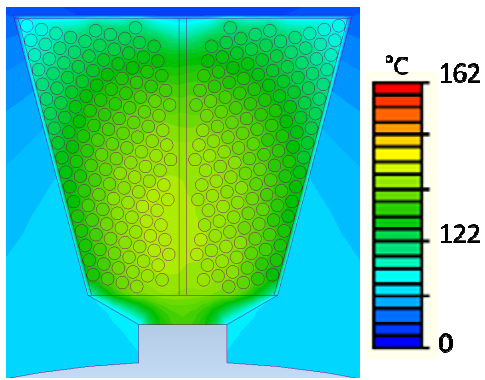

(d)
Fig. 10: (a) EM heat source in Version \#3, (b) EM heat source in Version\#4 (c) Temperature in the slot for Version \#3, (d) Temperature in the slot for Version \#4

higher uneven current sharing among the parallel strands. On the other hand, in version \#4, the parallel strands of each bundle are grouped towards the vertical direction (along the slot height) where the overall change in flux density is smaller for this case. The improved current sharing for version \#4 with respect to that in version \#3 is evident from Fig. 7.

A 2-D thermal FEA simulation is carried out to evaluate the thermal performances of the two configurations (Version \#3 and \#4). The thermal model includes a single slot, two adjacent half teeth and the corresponding back iron as shown in Fig 9. As the motor is water jacket cooled, a constant temperature of $95^{\circ} \mathrm{C}$
TABLE V

SPECIFICATION OF VALIDATION MOTORETTE

\begin{tabular}{cc}
\hline \hline Parameter & Value \\
\hline \hline Strands - in - hand & 5 \\
Turns per phase & 8 \\
Copper dimeter (mm) & 1.25 \\
Total strands per slot & 80 \\
Slot Filling factor (\%) & 20 \\
Stack Length (mm) & 60 \\
\hline \hline
\end{tabular}

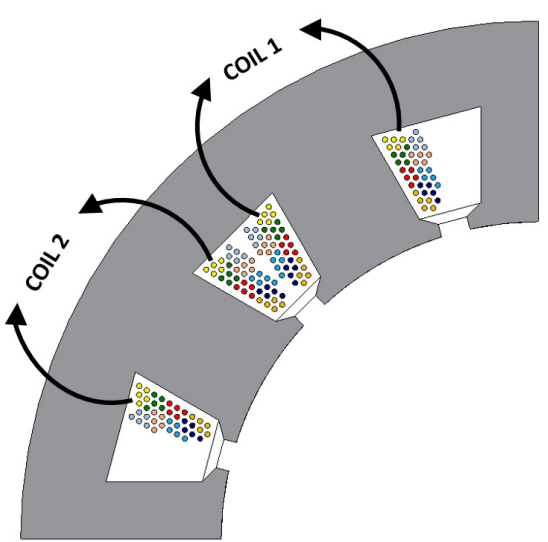

Fig. 11. Representation of motorette used for experimental validation

representing cooling from the stator back iron to the water jacket housing is applied to the back iron outer surface, and periodic conditions are applied to the middle plane of the two adjacent teeth. An adiabatic boundary condition is assumed at the top surface of the slot (towards the slot top). The heat generated in the individual strands obtained from electromagnetic (EM) FEA is applied into the thermal model for analysis. Fig. 10a and 10b show the EM heat sources in the slot and Fig. 10c and 10d show the temperature distribution inside the slot for Version \#3 and \#4 of models in TABLE IV respectively. The peak temperature for Version \#3 is $161.6^{\circ} \mathrm{C}$, while for Version $\# 4$ it is $138.9^{\circ} \mathrm{C}$. Thus, by the accurate conductor placement and bundle shaping the peak temperature in the slot is reduced by over $20^{\circ} \mathrm{C}$, with corresponding cost and reliability benefits.

\section{VALIDATION}

The previous section has highlighted some interesting findings with regards to conductor positioning and $\mathrm{AC}$ losses, and in this section experimental validation is sought. For validation purposes, a simpler motorette model is considered as shown in Fig. 11 and detailed in TABLE $\mathrm{V}$.

\section{A. FE Modelling and Analysis}



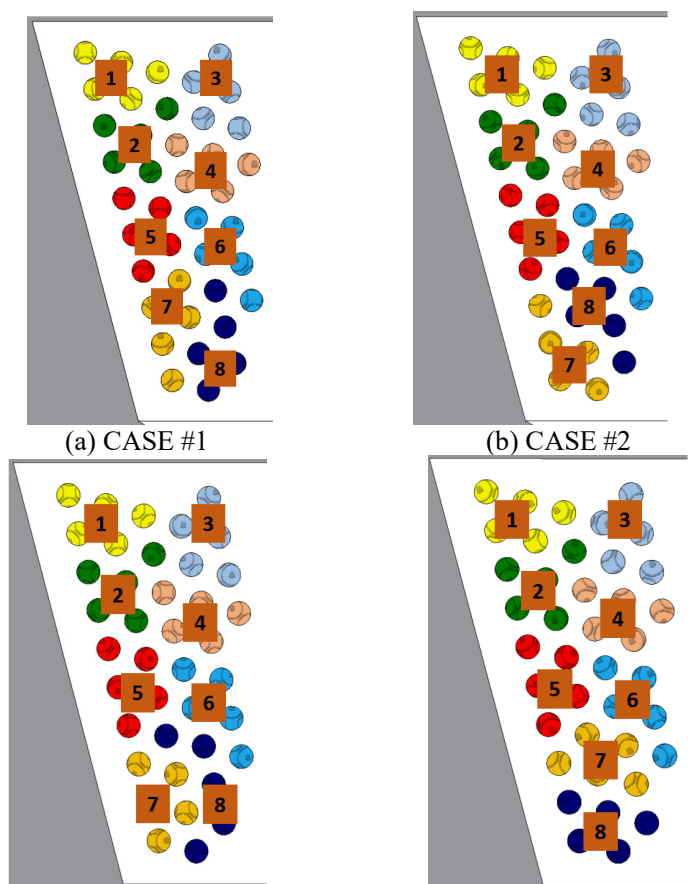

(c) CASE \#3

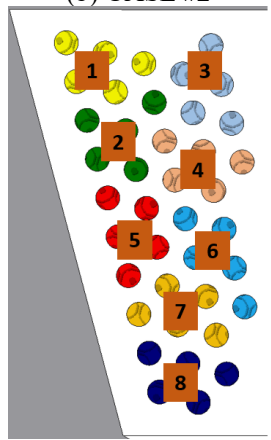

(d) CASE \#4

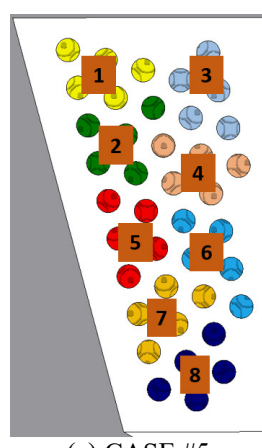

(e) CASE \#5

Fig. 12. Half side of the slot showing various cases with plausible bundle positions

COIL 1

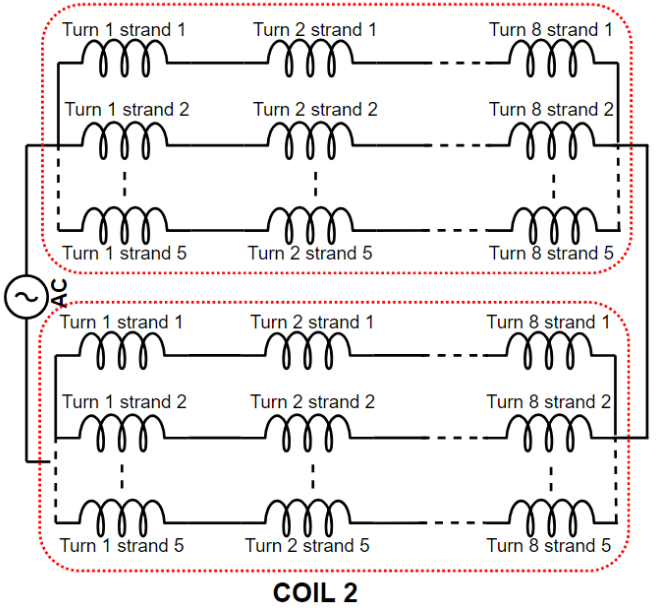

Fig. 13. Representation of strand circuital connection in the validation motorette

Five cases of bundle layout are modelled and analyzed

TABLE VI

COMPARISON OF TOTAL LOSS TO DC LOSS IN ACTIVE LENGTH

\begin{tabular}{ccc}
\hline \hline \multirow{2}{*}{ CASE \# } & $\begin{array}{c}\text { Active length Total Loss } \\
\text { (W) }\end{array}$ & Total / DC Loss \\
\hline \hline CASE \#1 & 21.86 & 4.27 \\
CASE \#2 & 23.18 & 4.53 \\
CASE \#3 & 19.31 & 3.78 \\
CASE \#4 & 13.39 & 2.62 \\
CASE \#5 & 13.24 & 2.59 \\
\hline \hline
\end{tabular}

using FEA. Similar to the process described in subsection II-B, only the top two bundles (bundles 7 and 8) shapes are changed. A supply current of 30 Arms is used, with the five cases (CASE\#1 - CASE\#5) shown in Fig. 12 and the corresponding circuital connections shown in Fig. 13.

TABLE VI shows the calculated losses in the active length of the motorette corresponding to Cases \#1 - \#5 of Fig.12. The DC loss of the motorette is $5.1 \mathrm{~W}$. At 1500 $\mathrm{Hz}$, Case \#2 has the highest active length loss of $23.18 \mathrm{~W}$ with a total to DC loss ratio of 4.53 , while Case \#5 has the lowest loss of $13.24 \mathrm{~W}$ and a corresponding total to DC loss ratio of 2.59 .

Again, to explain the notable difference which occurs between the two cases (\#2, and \#5), a similar explanation as described in previous section is presented. In Fig. 14a, the flux density in the region of interest within the slot is plotted, with the red circles representing the strands that form bundles 7 and 8 . The region of the slot occupied by these strands is divided into four quadrants, namely, Q1 to Q4. For each quadrant, the average flux density $|\mathrm{B}|$ is calculated over one electrical cycle. The $|\mathrm{B}|$ for each quadrant is highlighted in green in Fig. 14a. The percentage change in $|\mathrm{B}|$ from one quadrant to another is highlighted in yellow and enclosed within the white

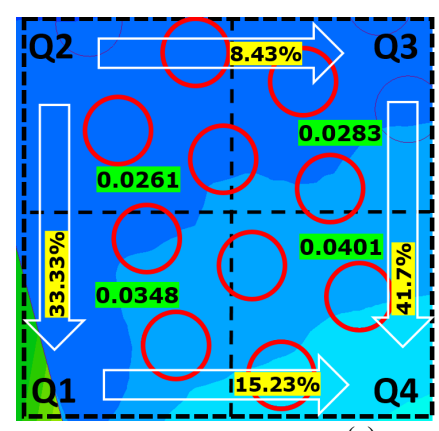

(a)

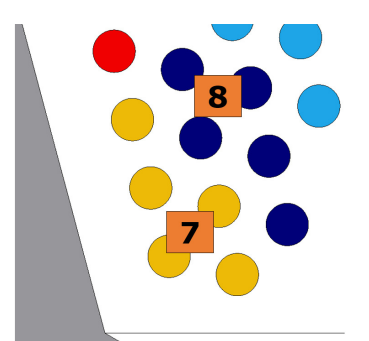

(b)
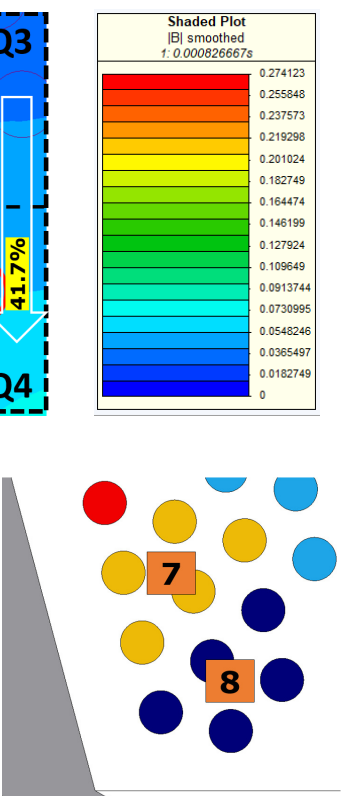

(c)
Fig. 14: (a) Average value of flux density $|\mathrm{B}|$ in the quadrants, (b) bundles 7 and 8 in CASE 2, (c) bundles 7 and 8 in CASE 5 


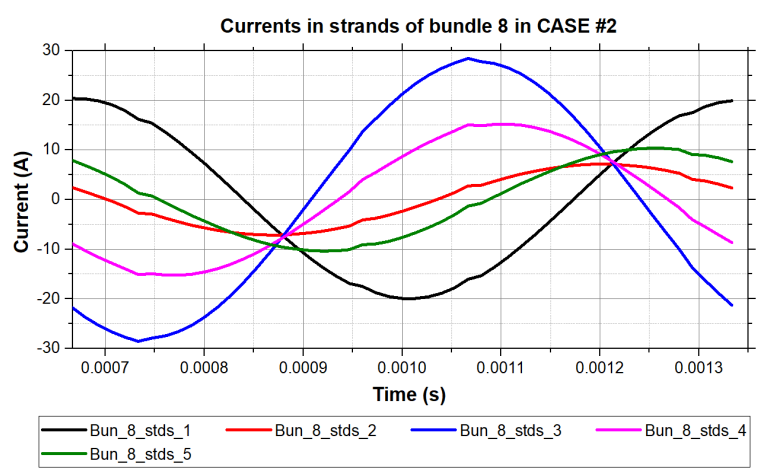

(a)

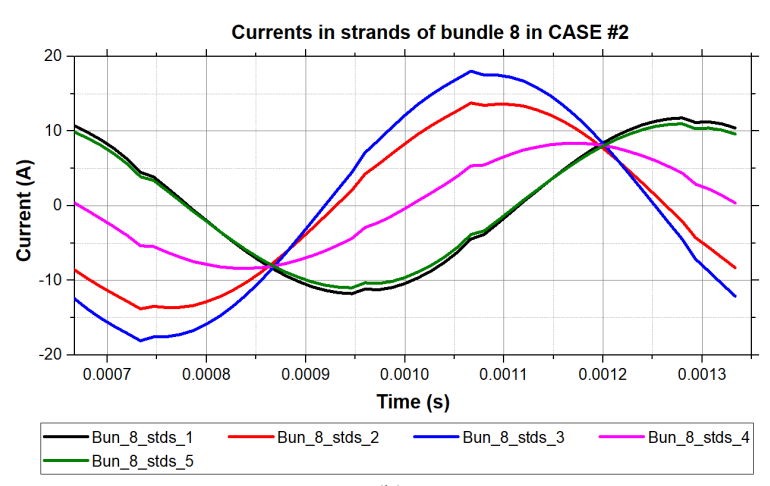

(b)

Fig. 15. Comparison of strand currents in bundle 8 of CASE \#2 and \#5

arrows. This change is quite marked along the vertical direction i.e. from Q1 to Q2 at 33.33\% and from Q3 to Q4 at $41.7 \%$, when compared to that in the horizontal direction, with Q1 to Q4 being $15.23 \%$ and Q2 to Q3 being $8.43 \%$. Figs. $14 \mathrm{~b}$ and $14 \mathrm{c}$ show the bundles 7 and 8 positions for Case \#2 and Case \#5 respectively. In Case $\# 2$, since the parallel strands within the bundles are vertically aligned, they are subjected to an overall greater variation of flux density (33.33\% from Q2 to Q1 and 41.7\% from Q3 to Q4). On the other hand, in Case \#5, the parallel strands of each bundle are grouped towards the horizontal direction where the change in flux density is smaller (15.23\% from Q1 to Q4 and 8.43\% from Q2 to Q3) and thus the parallel strands are linking more or less similar flux. The improved current sharing for Case \#5 with respect to that in Case \#2 is evident from Fig. 15.

As can be seen from this figure, in Case \#2, the peak current in the strands deviates from the ideal peak current by $92 \%$ while in Case $\# 5$ it deviates by a significantly lower $48 \%$.

\section{B. Experimental Validation}

For the experimental verification, motorette Case \#2 and Case \#5 are considered. Benefiting from the advancements in precision 3D printing, formers are manufactured, as shown in Fig.16, and used to fix exactly the position of the individual strands in an identical fashion to the ones considered in the FE analysis. Fig. 17a

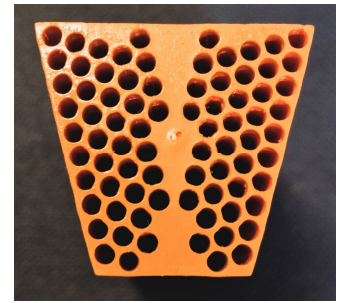

(a) Front View

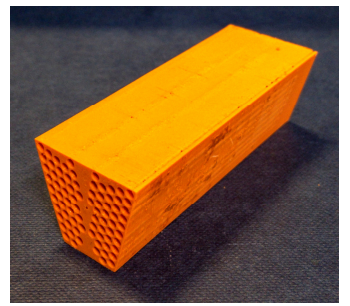

(b) Isometric View
Fig. 16. Front and Isometric views for 3D printed former used within experimental validation

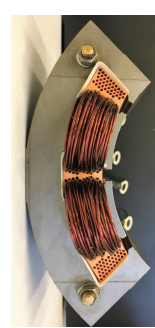

(a)

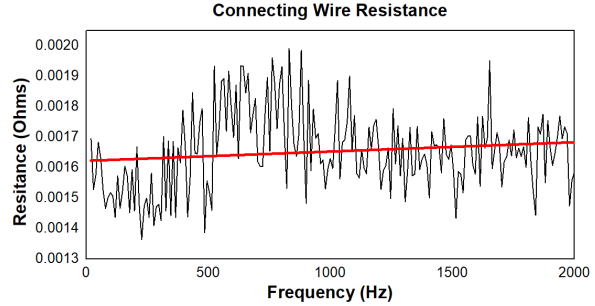

(b)
Fig. 17. (a) A wound motorette, (b) AC resistance of connecting cable

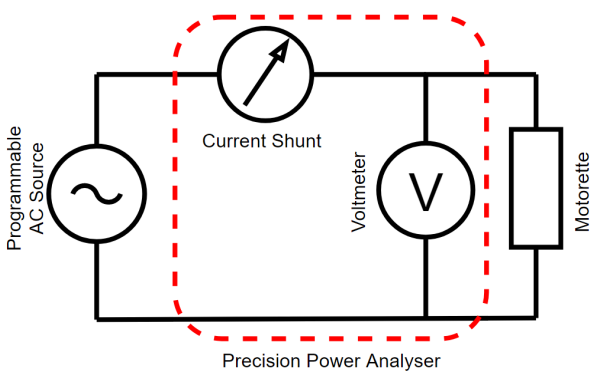

Fig. 18. Schematic diagram of experimental setup showing equipment and connection

shows a wound motorette using the aforesaid formers. An impedance analyzer is used to measure the resistance of the lead wires, crimp contacts and the connecting cables, up to very high frequencies $(2 \mathrm{MHz})$ and it is observed that the resistance did not change significantly in the range of frequencies of interest for this study (as shown in Fig. 17b). This is due to the short length of the connecting cables, as well as their construction being made of fine insulated and twisted strands.

Fig. 18 shows the schematic of the experimental setup and Fig. 19 shows the actual experimental setup for the AC loss measurement. A variable frequency power supply (Programmable AC source, CHROMA 61511) is used as the power source. A precision power analyser (PPA 5530 from N4L) is used for measuring the power loss in the experimental setup. Since, the power analyser has an overload capacity of 32A, a current amplitude of $30 \mathrm{Arms}$, is injected into the coils for all the measured frequencies. Temperature is monitored in real-time using K-type thermocouples (connected to PICO TC-08 data logger) placed inside the slot and at the end-windings. This 


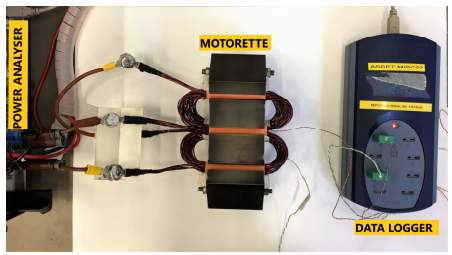

(a) View 1

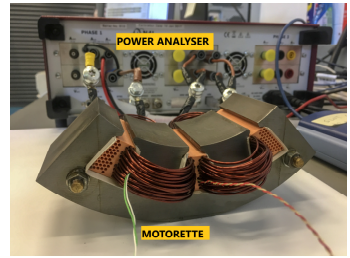

(b) View 2
Fig. 19. Views of experimental setup showing equipment used in the tests

ensures that temperature effects on winding resistance can be accounted for.

Tables VII and VIII detail the comparison of simulated losses and experimentally measured losses for a range of frequencies varying from $20 \mathrm{~Hz}$ all the way up to $1.5 \mathrm{kHz}$. Here, the column 'Active length loss' represents the 2DFEA-computed winding loss (only the part of the winding within the stator stack length considered, i.e. not including the end-windings). The column 'Total Simulated loss' represents the active length loss added with the I2R loss of the auxiliary components (end winding, lead wires, crimp contacts, connecting cables) and the core loss as computed from FEA. The column 'Total Experimental Loss' represents the total experimentally-measured loss of the motorette setup (with the auxiliary components connected). Finally, the column 'Total/DC loss (Exp.) ' represents the ratio of total experimentally measured loss minus the 2D-FEA computed core loss at high frequency to the total experimentally-measured DC loss of the setup. The simulated and experimental total losses are in close matching. For clarity, it should be pointed out that in TABLES VII and VIII, the end-winding losses are factored in. In agreement with the analysis prediction of the preceding section, there is a significant drop in the Total / DC loss ratio for Case \#5 when compared to Case \#2. Since, most of the AC losses occur within the active length of the machine, at $1500 \mathrm{~Hz}$, the armature losses drop by a significant $36 \%$ in the active length of motorette for CASE \#5 when compared to CASE \#2.

For the research conducted in this paper, the winding process is manual (i.e. hand wound), however given the promising results, investigation has been carried out for its adaptation in a fully automated winding process. For an automated winding process, a needle-winding process would be adopted in conjunction with the 3D-printed module, which would translate to a winding speed of around 2000 turns/minute, which is around 6 times slower with respect to the flyer-winding technology currently in use with the existing traction machine [22]. Hence, this drawback of reduction of winding speed would need to be considered in conjunction with the benefits of reduced $\mathrm{AC}$ losses.

\section{CONCLUSION}

This paper provides a comprehensive analysis and design recommendations on the impact of bundle shapes
TABLE VII

LOSSES IN MOTORETTE CASE \#2

\begin{tabular}{ccccc}
\hline \hline \multicolumn{5}{c}{ Motorette CASE \#2 } \\
\hline $\begin{array}{c}\text { Freq. } \\
(\mathrm{Hz})\end{array}$ & $\begin{array}{c}\text { Active length } \\
\text { Loss (W) }\end{array}$ & $\begin{array}{c}\text { Total Simulated } \\
\text { Loss (W) }\end{array}$ & $\begin{array}{c}\text { Total Exp. } \\
\text { Loss (W) }\end{array}$ & $\begin{array}{c}\text { Total/DC loss } \\
\text { (Exp.) }\end{array}$ \\
\hline \hline 20 & 5.09 & 16.69 & 17.28 & 1.00 \\
50 & 5.08 & 16.71 & 17.85 & 1.03 \\
100 & 5.36 & 17.04 & 18.02 & 1.04 \\
300 & 6.061 & 18.03 & 19.59 & 1.11 \\
500 & 7.72 & 20.07 & 21.99 & 1.23 \\
666.67 & 9.4 & 22.11 & 23.69 & 1.31 \\
1500 & 23.89 & 39.10 & 42.35 & 2.24 \\
\hline \hline
\end{tabular}

TABLE VIII

LOSSES IN MOTORETTE CASE \#5

\begin{tabular}{|c|c|c|c|c|}
\hline \multicolumn{5}{|c|}{ Motorette CASE \#5 } \\
\hline $\begin{array}{l}\text { Freq. } \\
(\mathrm{Hz})\end{array}$ & $\begin{array}{l}\text { Active length } \\
\text { Loss (W) }\end{array}$ & $\begin{array}{l}\text { Total Simulated } \\
\text { Loss (W) }\end{array}$ & $\begin{array}{l}\text { Total Exp. } \\
\text { Loss (W) }\end{array}$ & $\begin{array}{c}\text { Total/DC } \\
\text { loss (Exp.) }\end{array}$ \\
\hline 20 & 5.14 & 16.78 & 17.55 & 1.00 \\
\hline 50 & 5.18 & 16.84 & 17.63 & 1.00 \\
\hline 100 & 5.19 & 16.91 & 17.52 & 1.01 \\
\hline 300 & 5.54 & 17.54 & 18.24 & 1.02 \\
\hline 500 & 6.23 & 18.62 & 19.72 & 1.08 \\
\hline 666.67 & 6.95 & 19.70 & 21.16 & 1.14 \\
\hline 1500 & 13.24 & 28.49 & 34.00 & 1.73 \\
\hline
\end{tabular}

and conductor positions on the AC losses in high frequency machine windings. A method for simplification of the finite element analysis model was discussed which allows for comparatively quicker computation times at the expense of a negligible reduction in computational accuracy.

Using the computationally efficient analysis model, various plausible versions of conductor positions and bundle shapes were modelled. AC losses for each version were analyzed and improved, and a version where the $\mathrm{AC}$ losses in the active section reduce by around 50\% with respect to the worst-case scenario was achieved. A detailed comparative analysis of the worst-case and bestcase versions was made with some interesting observations. Most importantly, the aforesaid marked reduction of the $\mathrm{AC}$ losses can be rooted to the layout of the strands within the top section of the slot, where it is advised that within this section, the strands pertaining to the different bundles are organized as such that to minimize the variation of flux linkage within the parallel strands.

Benefitting from advancements in 3D printing, a precise coil former was printed and used to experimentally verify this hypothesis and design recommendation on a simplified motorette section. A $36 \%$ reduction in the net winding $\mathrm{AC}$ losses is experimentally verified simply by the accurate controlling of the conductors within the top of 
the slot, without impacting the losses at low frequencies. This finding can help with the improvement of power density in high frequency machines, and will be inevitably further aided with the rapid advancements in printing and manufacturing techniques.

\section{REFERENCES}

[1] D. Gerada, A. Mebarki, N. L. Brown, C. Gerada, A. Cavagnino, and A. Boglietti, "High-Speed Electrical Machines: Technologies, Trends, and Developments," IEEE Transactions on Industrial Electronics, vol. 61, no. 6, pp. 2946-2959, 2014.

[2] D. Golovanov, L. Papini, D. Gerada, Z. Xu, and C. Gerada, "Multidomain Optimization of High-Power-Density PM Electrical Machines for System Architecture Selection," IEEE Transactions on Industrial Electronics, vol. 65, no. 7, pp. 5302-5312, 2018.

[3] A. M. El-Refaie, "Fractional-Slot Concentrated-Windings Synchronous Permanent Magnet Machines: Opportunities and Challenges," IEEE Transactions on Industrial Electronics, vol. 57, no. 1, pp. 107-121, 2010

[4] R. Wrobel, P. H. Mellor, and D. Holliday, "Thermal Modeling of a Segmented Stator Winding Design," IEEE Transactions on Industry Applications, vol. 47, no. 5, pp. 2023-2030, 2011.

[5] D. Bauer, P. Mamuschkin, H. C. Reuss, and E. Nolle, "Influence of parallel wire placement on the AC copper losses in electrical machines," in 2015 IEEE International Electric Machines \& Drives Conference (IEMDC), 2015, pp. 1247-1253.

[6] I. Petrov, M. Polikarpova, P. Ponomarev, P. Lindh, and J. Pyrhönen, "Investigation of additional AC losses in tooth-coil winding PMSM with high electrical frequency," in 2016 XXII International Conference on Electrical Machines (ICEM), 2016, pp. 1841-1846.

[7] D. Gerada et al., "Holistic electrical machine optimization for system integration," in 2017 IEEE 3rd International Future Energy Electronics Conference and ECCE Asia (IFEEC 2017 - ECCE Asia), 2017, pp. 980-985.

[8] G. J. Atkinson, B. C. Mecrow, A. G. Jack, D. J. Atkinson, P. Sangha, and M. Benarous, "The Analysis of Losses in High-Power Fault-Tolerant Machines for Aerospace Applications," IEEE Transactions on Industry Applications, vol. 42, no. 5, pp. 11621170, 2006.

[9] S. Iwasaki, R. P. Deodhar, Y. Liu, A. Pride, Z. Q. Zhu, and J. J. Bremner, "Influence of PWM on the Proximity Loss in PermanentMagnet Brushless AC Machines," IEEE Transactions on Industry Applications, vol. 45, no. 4, pp. 1359-1367, 2009.

[10] P. H. Mellor, R. Wrobel, and N. McNeill, "Investigation of Proximity Losses in a High Speed Brushless Permanent Magnet Motor," in Conference Record of the 2006 IEEE Industry Applications Conference Forty-First IAS Annual Meeting, 2006, vol. 3, pp. 1514-1518.

[11] A. S. Thomas, Z. Q. Zhu, and G. W. Jewell, "Proximity Loss Study In High Speed Flux-Switching <newline/>Permanent Magnet Machine," IEEE Transactions on Magnetics, vol. 45, no. 10, pp. 4748-4751, 2009.

[12] M. v. d. Geest, H. Polinder, J. A. Ferreira, and D. Zeilstra, "Stator winding proximity loss reduction techniques in high speed electrical machines," in 2013 International Electric Machines \& Drives Conference, 2013, pp. 340-346.

[13] P. Mellor, R. Wrobel, D. Salt, and A. Griffo, "Experimental and analytical determination of proximity losses in a high-speed PM machine," in 2013 IEEE Energy Conversion Congress and Exposition, 2013, pp. 3504-3511.

[14] M. Popescu and D. G. Dorrell, "Proximity Losses in the Windings of High Speed Brushless Permanent Magnet AC Motors With Single Tooth Windings and Parallel Paths," IEEE Transactions on Magnetics, vol. 49, no. 7, pp. 3913-3916, 2013.

[15] P. B. Reddy and T. M. Jahns, "Analysis of bundle losses in high speed machines," in The 2010 International Power Electronics Conference - ECCE ASIA -, 2010, pp. 2181-2188

[16] P. B. Reddy, T. M. Jahns, and T. P. Bohn, "Transposition effects on bundle proximity losses in high-speed PM machines," in 2009 IEEE Energy Conversion Congress and Exposition, 2009, pp. 1919-1926.
[17] P. B. Reddy, T. M. Jahns, and T. P. Bohn, "Modeling and analysis of proximity losses in high-speed surface permanent magnet machines with concentrated windings," in 2010 IEEE Energy Conversion Congress and Exposition, 2010, pp. 996-1003.

[18] P. B. Reddy, Z. Q. Zhu, S. H. Han, and T. M. Jahns, "Strand-level proximity losses in PM machines designed for high-speed operation," in 2008 18th International Conference on Electrical Machines, 2008, pp. 1-6.

[19] M. Vetuschi and F. Cupertino, "Minimization of Proximity Losses in Electrical Machines With Tooth-Wound Coils," IEEE Transactions on Industry Applications, vol. 51, no. 4, pp. 30683076,2015

[20] A. Tessarolo, F. Agnolet, F. Luise, and M. Mezzarobba, "Use of Time-Harmonic Finite-Element Analysis to Compute Stator Winding Eddy-Current Losses Due to Rotor Motion in Surface Permanent-Magnet Machines," IEEE Transactions on Energy Conversion, vol. 27, no. 3, pp. 670-679, 2012.

[21] A. Bardalai et al., "The Influence of Strands and Bundle-Level Arrangements of Magnet Wires on AC Losses in the Winding of High - Speed Traction Machine," in 2018 21st International Conference on Electrical Machines and Systems (ICEMS), 2018, pp. 65-69.

[22] J. Hagedorn, F. Sell-Le-Blanc, J. Fleisher, Handbook of Coil Winding - Technologies for efficient electrical wound products and their automated production. Springer-Verlag GmbH Germany, 2018. 